Research Article

\title{
Prevalence and Risk Factors of Cytopenia in HIV-Infected Patients before and after the Initiation of HAART
}

\author{
Lina Fan $(\mathbb{D}$, Cuilin Li $\mathbb{D}$, and Hongxin Zhao $\mathbb{C}$ \\ Clinical and Research Center of Infectious Diseases, Beijing Ditan Hospital, Capital Medical University, Beijing 100015, China \\ Correspondence should be addressed to Hongxin Zhao; 13911022130@163.com
}

Received 3 June 2019; Revised 17 August 2019; Accepted 7 September 2019; Published 29 January 2020

Academic Editor: Surender Khurana

Copyright (c) 2020 Lina Fan et al. This is an open access article distributed under the Creative Commons Attribution License, which permits unrestricted use, distribution, and reproduction in any medium, provided the original work is properly cited.

Background. Cytopenia is a frequent hematological disorder in patients with human immunodeficiency virus (HIV) infection. However, the distribution and risk factors of cytopenia in patients starting highly active anti-retrovirus treatment (HAART) and the effect of HAART on cytopenia were not fully investigated. Methods. From November 2004 to August 2016, a retrospective study was conducted to evaluate the prevalence of cytopenia in 4325 HAART-naïve patients. Risk factors of cytopenia at baseline and on recovery from cytopenia were analyzed using logistic regression analysis after 24 months of HAART in Beijing Ditan Hospital. Results. The prevalence of cytopenia was $19.1 \%$ in HIV-naïve patients. Risk factors for cytopenia in HAART-naïve patients were a CD4 cell count $<200$ cells $/ \mu \mathrm{L}$, femaleness, WHO stage IV, coinfection with hepatitis B virus $(\mathrm{HBV}), \mathrm{BMI}<18.5 \mathrm{~kg} /$ $\mathrm{m}^{2}$, a viral load $\geq 100,000$ copies $/ \mathrm{ml}$, and age $\geq 40$ years. In total, $70.2 \%$ and $76.4 \%$ of patients with cytopenia recovered after 6 and 24 months of HAART, respectively. The predictors of patients without normal blood cells after 24 months HAART were a CD4 cell count of $<200$ cells $/ \mu \mathrm{L}$ at baseline, femaleness, WHO stage IV, coinfection with HBV, and treatment with AZT. Conclusion. Early detection could decrease the prevalence of HIV-related cytopenia, while starting HAART as early as possible seems to be effective for normalization of the blood cells in HIV-infected patients.

\section{Introduction}

Cytopenia is a frequent hematological disorder in patients with human immunodeficiency virus (HIV) infection. The most common manifestation is reduction of any of the blood cell lines, leading to neutropenia, anemia, and thrombocytopenia. Previous studies have reported prevalence rates of anemia, neutropenia, and thrombocytopenia of 1.3\%-95\% $[1], 10 \%-85 \%[2,3]$, and $7 \%-21 \%[4,5]$, respectively; the wide span reflects the different definitions, geographical locations, race/ethnicity of patients, and stages of disease. Lower $\mathrm{CD} 4^{+} \mathrm{T}$-cell counts, higher viral loads, advanced disease stages, and side effects of medicines used for HIV were risk factors for cytopenias in HIV-infected patients [5].

In HIV-infected patients, cytopenia has been associated with the progression to AIDS (anemia), high mortality (anemia), hospitalization (all), and secondary infections caused by bacterial and fungal pathogens (neutropenia) or drugs used for HIV [6-11]. Highly active antiretroviral therapy (HAART) has been proven to reduce AIDS-related mortality significantly and leads to improvements in cytopenia $[9,12-16]$. However, some antiretroviral compounds such as zidovudine (AZT) also exert bone marrow cytotoxicity and contribute to cytopenia in HIV-infected patients $[9,13,17]$. Monitoring changes in hematological parameters in HIV-infected patients while they are on HAART could be a useful indicator of the patient response to HAART.

In China, Dai et al. found that the prevalence of anemia was $9.76 \%$ [6], while Fan et al. reported a thrombocytopenia rate of $4.5 \%$ among 1730 patients [18]. Shen reported that the prevalence rates of leukopenia and thrombocytopenia were $33.2 \%$ and $15.6 \%$ [19]. However, the prevalence rates 
and risk factors of cytopenia and the effect of HAART on cytopenia have not been well documented. This study was designed to investigate the prevalence and risk factors of cytopenia among HAART-naïve patients. Furthermore, we aimed to evaluate the effect of HAART on cytopenia.

\section{Materials and Methods}

2.1. Study Subjects. In total, $5047 \mathrm{HIV}$-infected patients who were on follow-up after HAART at the Department of Infectious Diseases, Beijing Ditan Hospital, Capital Medical University, from November, 2004 to August, 2016, were included in this study. This study was approved by the ethics committees of Beijing Ditan Hospital, Capital Medical University, and the study conformed to the Declaration of Helsinki. The profiles of 722 participants were excluded because of neutrophilia $(n=108)$ or incomplete information $(n=613)$. Finally, a total of 4325 patients were included. The demographic and clinical data for the HAART-naive patients including sex, age, height, weight, route of transmission, the initial time of HAART treatment, and WHO stage were collected. Laboratory data such as absolute neutrophil numbers, hemoglobin concentration, absolute platelet count, and absolute $\mathrm{CD} 4^{+} \mathrm{T}$-cell count were collected at baseline.

To investigate the effect of HAART on cytopenia, 824 $\mathrm{HIV}$-infected patients with cytopenia were followed up to 24 months after the initiation of HAART. The exclusion criteria were all patients without cytopenia $n=3501$, patients who were lost at follow-up $n=48$, fatalities $n=23$, irregular follow-up times $n=73$, and lack of follow-up time points ( $>2$ follow-up time points) $n=69$. In total, 213 patients were excluded and $611 \mathrm{HIV}$-infected patients with cytopenia were included. The number of neutrophils, the platelet count, the $\mathrm{CD} 4^{+} \mathrm{T}$-cell count, and the hemoglobin concentration at 6,12 and 24 months after the initiation of HAART were recorded. The flow chart is shown in Figure 1.

2.2. Definition. Conditions were defined based on the following parameters. Anemia: hemoglobin $<11 \mathrm{~g} / \mathrm{dL}$ in women or $<12 \mathrm{~g} / \mathrm{dL}$ in men [20]; neutropenia: neutrophil count $<2000$ cells $/ \mu \mathrm{L}$; thrombocytopenia: platelet count $<100,000$ cells $/ \mu \mathrm{L}$. Patients with isolated anemia, thrombocytopenia or neutropenia were defined as patients with unicytopenia. Bicytopenia was defined as a patient in whom any two of the three lineage cell counts (neutrophils, hemoglobin, or platelets) were below the levels designated above. Pancytopenia was defined as having three lineage cell counts (neutrophils, hemoglobin, or platelets) below the levels designated above.

2.3. Data Collection. Retrospective data were collected from medical records, including demographic, clinical, and laboratory characteristics. Variables include age, sex, HIV transmission route, coinfection with $\mathrm{HBV}$, coinfection with $\mathrm{HCV}, \mathrm{WHO}$ staging, HIV viral load, the use of AZT and stavudine (D4T), and body mass index (BMI). Age was

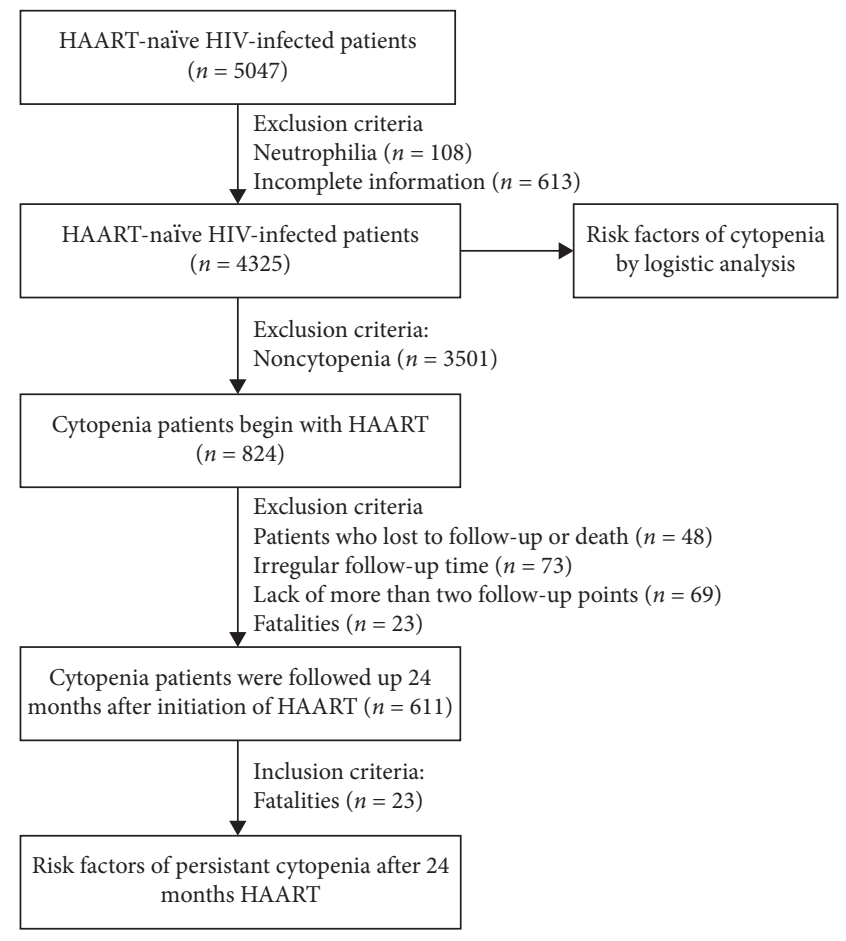

FIgURE 1: Flow chart of this study.

categorized as $<40$ and over 40 years. Based on Chinese guidelines for diagnosis and treatment of HIV/AIDS, CD4 T-cell count was categorized as $<200$ cells/ $\mu$ l and over 200 cells/ $\mu \mathrm{l}$ [21]. Based on the WHO clinical staging of HIV disease in adults and adolescents, subjects were classified in to stage I, stage II, stage III, and stage IV [22]. The cutoff for BMI for defining underweight was $<18.5 \mathrm{~kg} / \mathrm{m}^{2}$ and overweight and obesity was $>24.0 \mathrm{~kg} / \mathrm{m}^{2}[23,24]$. HIV viral load was categorized as $<100000$ copies/ml and over 100000 copies/ml [25].

2.4. Statistical Analysis. All statistical analyses were performed using SPSS 22.0 software (SPSS, Chicago, IL, USA) and GraphPad 7 (GraphPad Software, La Jolla, CA, USA). Data were presented as the medians with interquartile ranges (IQR) due to skewed statistical distributions, while categorical variables were presented by percentages. The differences between two groups were analyzed using the Mann-Whitney $U$ test (nonparametric). A Pearson's test was used to evaluate differences in categorical variables. Binary logistic regression analysis or ordinal logistic regression analysis was used to evaluate risk factors associated with cytopenias and persistent cytopenia after 24 months of HAART. Demographic variables (sex and age) and clinical/laboratory characteristics $\left(\mathrm{CD} 4^{+} \mathrm{T}\right.$-cell count, $\mathrm{BMI}$, WHO staging, viral load, transmission routes, coinfection with $\mathrm{HBV}$, and coinfection with $\mathrm{HCV}$ ) were included to investigate for the risk factor of cytopenia. The risk factors of persistent cytopenia investigated included demographic variables (sex and age) and clinical/ laboratory variables $\left(\mathrm{CD} 4^{+} \mathrm{T}\right.$-cell count at baseline and 
TABLe 1: The demographic and clinical characteristics of participants.

\begin{tabular}{|c|c|c|c|}
\hline Characteristics & Total $(n=4325)$ & Noncytopenia $(n=3501)$ & Cytopenia $(n=824)$ \\
\hline \multicolumn{4}{|l|}{ Age (years) } \\
\hline$<40$ & $2796(64.6 \%)$ & $2442(67.6 \%)$ & $354(49.8 \%)$ \\
\hline$\geq 40$ & $1530(35.4 \%)$ & $1173(32.4 \%)$ & $357(50.2 \%)$ \\
\hline \multicolumn{4}{|l|}{ Sex } \\
\hline Male & $4048(93.6 \%)$ & $3340(95.4 \%)$ & $708(85.9 \%)$ \\
\hline Female & $277(6.4 \%)$ & $161(4.6 \%)$ & $116(14.1 \%)$ \\
\hline \multicolumn{4}{|l|}{ WHO stage } \\
\hline I & $3307(76.5 \%)$ & $2795(79.8 \%)$ & $512(62.1 \%)$ \\
\hline II & $234(5.4 \%)$ & $188(5.4 \%)$ & $46(5.6 \%)$ \\
\hline III & $281(6.5 \%)$ & $217(6.2 \%)$ & $64(7.8 \%)$ \\
\hline \multirow{2}{*}{\multicolumn{4}{|c|}{ BMI $\left(\mathrm{kg} / \mathrm{m}^{2}\right)$}} \\
\hline & & & \\
\hline$<18.5$ & $337(9.8 \%)$ & $240(8.1 \%)$ & $97(19.7 \%)$ \\
\hline $18.5-24$ & $2248(65.3 \%)$ & $1938(65.7 \%)$ & $310(62.9 \%)$ \\
\hline$>24$ & $858(24.9 \%)$ & $772(26.2 \%)$ & $86(17.4 \%)$ \\
\hline \multicolumn{4}{|c|}{$\mathrm{CD}^{+}{ }^{+} \mathrm{T}$-cell counts $(/ \mu \mathrm{l})$} \\
\hline$<200$ & $1475(35.6 \%)$ & $949(22.9 \%)$ & $526(66.2 \%)$ \\
\hline$\geq 200$ & $2667(64.4 \%)$ & $2398(71.6 \%)$ & $269(33.8 \%)$ \\
\hline \multicolumn{4}{|c|}{ Viral load (copies/ml) } \\
\hline$\geq 100000$ & $979(30 \%)$ & $699(26.2 \%)$ & $280(48 \%)$ \\
\hline$<100000$ & $2280(70 \%)$ & $1977(73.9 \%)$ & $303(52 \%)$ \\
\hline \multicolumn{4}{|l|}{ Infection routes } \\
\hline Sexual & $3933(91 \%)$ & $3258(93.1 \%)$ & $675(81.9 \%)$ \\
\hline Others & $392(9.9 \%)$ & $243(6.9 \%)$ & $149(18.1 \%)$ \\
\hline \multicolumn{4}{|l|}{ HCV-coinfection } \\
\hline No & $3481(80.5 \%)$ & $2934(81.2 \%)$ & $547(76.9 \%)$ \\
\hline Yes & $77(19.5 \%)$ & $681(15.7 \%)$ & $164(23.1 \%)$ \\
\hline \multicolumn{4}{|l|}{ HBV-coinfection } \\
\hline No & $4111(95 \%)$ & $3474(96.1 \%)$ & $637(89.6 \%)$ \\
\hline Yes & $215(5 \%)$ & $141(3.9 \%)$ & $74(10.4 \%)$ \\
\hline
\end{tabular}

Note: data are presented as $n$ (\%); WHO, World Health Organization; BMI, body mass index; variable had missing values: $\mathrm{BMI}=883$; $\mathrm{HIV}$ RNA $=1066$; $\mathrm{CD} 4{ }^{+}$ T-cell counts $=183$

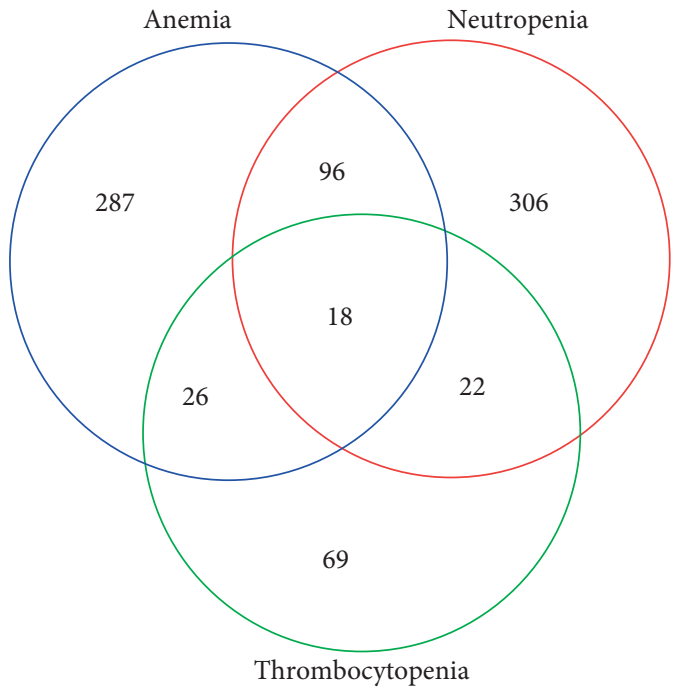

FIGURE 2: Distribution of cytopenia cases among the participants of the study.

after 24 months HAART, BMI, WHO staging at baseline, coinfection with HBV, and coinfection with HCV, viral load, and the use of AZT and D4T). Statistical significance was set at a level of $p<0.05$.

\section{Results}

3.1. The Demographic and Clinical Characteristics of HAARTNaïve Patients. A total of 4325 individuals were included in this study, of which $26.1 \%$ had a CD 4 cell count of $<200$ cells/ $\mu \mathrm{L}$. The median age was 36 years, the ratio of males to females was $15: 1$, the median BMI was $21.5(19.7,23.7) \mathrm{kg} / \mathrm{m}^{2}$, and the median $\mathrm{CD}^{+}$T-cell count was $249(151,356)$ cells $/ \mu \mathrm{L}$. Sexual transmission was mainly via the transmission route, which accounted for $91 \%$ of cases. According to WHO staging, stages II and III were present in 2541 (81.9\%) individuals (Table 1$)$.

3.2. The Prevalence and Distribution of Cytopenia in HAARTNaïve Patients. Cytopenia was detected in 824 (19.1\%) patients in our cohort, of which $662(15.3 \%)$ patients had unicytopenia, $144(3.3 \%)$ had bicytopenia, and $18(0.4 \%)$ had pancytopenia. Among the unicytopenia cases, 287 (6.63\%) patients had isolated anemia, $306(7.7 \%)$ had isolated neutropenia, and 69 (1.6\%) had isolated thrombocytopenia. Among the bicytopenia cases, 96 (2.2\%) had anemia and neutropenia, $26(0.6 \%)$ had anemia and thrombocytopenia, and $22(0.5 \%)$ had thrombocytopenia and neutropenia. The prevalence and distribution of cytopenia are shown in Figure 2. 

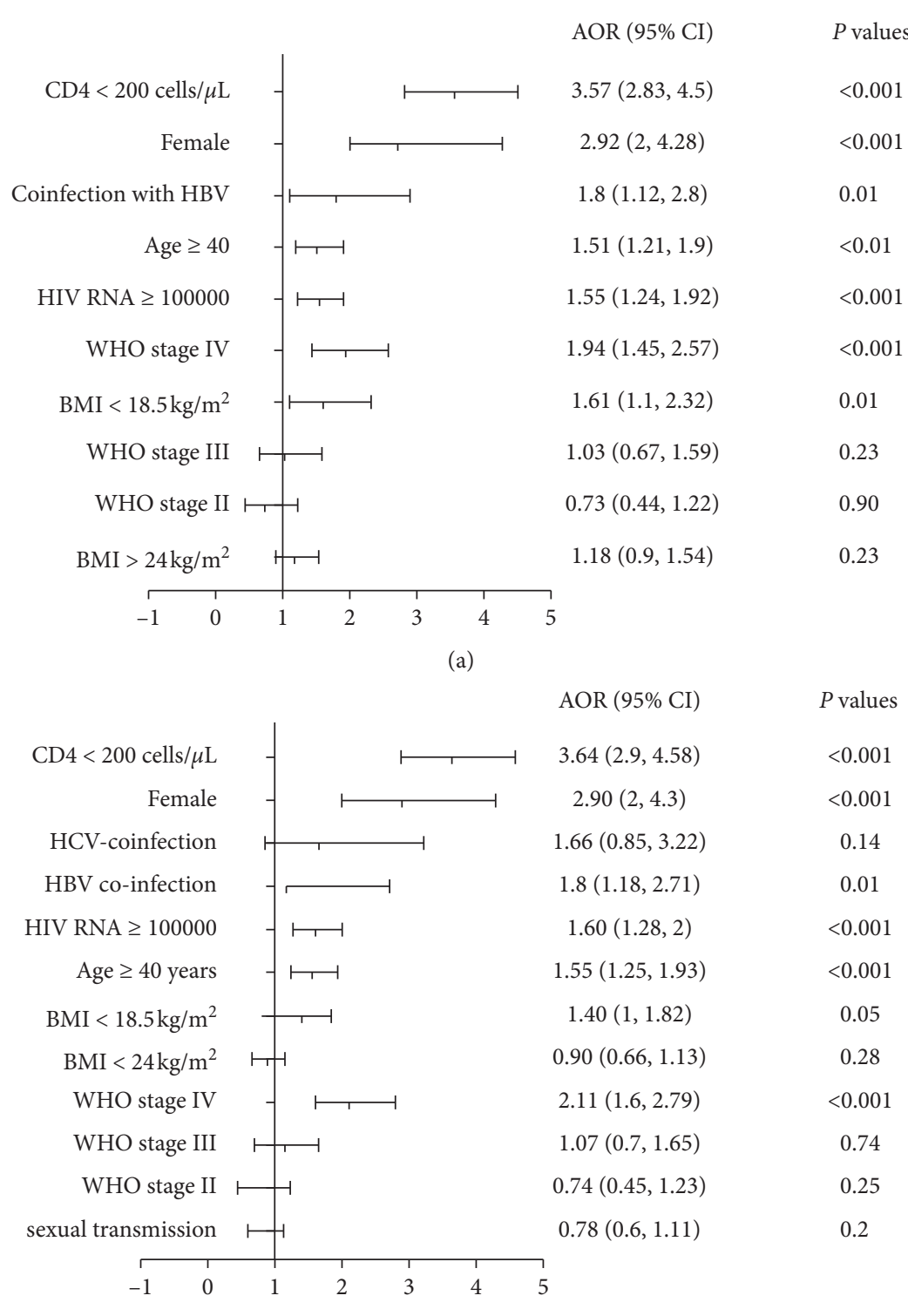

(b)

Figure 3: The forest plot of logistic analysis for cytopenias at baseline. (a) Binary logistic regression analysis for cytopenia. (b) Ordinal logistics regression analysis for unicytopenia, bicytopenia, and pancytopenia.

3.3. The Risk Factors for Cytopenia in HAART-Naïve Patients. As seen in Figure 3, multivariate logistic regression analyses were performed to investigate the risk factors of cytopenia in HAART-naïve patients. We found that a CD4 cell count $<200$ cells $/ \mu$ L (OR: 3.57, 95\% CI: 2.83-4.5, $p<0.001$ ), femaleness (OR: 2.92, 95\% CI: 2-4.28, $p<0.001$ ), WHO stage IV (OR: 1.94, 95\% CI: 1.45-2.57, $p<0.001$ ), coinfection with hepatitis B virus (HBV) (OR: 1.8, 95\% CI: 1.12-2.9, $p=0.007)$, BMI $<18.5 \mathrm{~kg} / \mathrm{m}^{2}$ (OR 1.61, 95\% CI: $1.1-2.32$, $p=0.01$ ), a viral load $>100,000$ (OR: $1.55,95 \%$ CI: $1.24-1.92$, $p<0.001$ ), and age $\geq 40$ years (OR: $1.51,95 \%$ CI: $1.21-1.9$, $p<0.01$ ) were all risk factors of cytopenia (Figure 3(a); Table 2). Cytopenia was not associated with HCV coinfection or transmission route.

Considering the distribution of cytopenia, we chose the ordinal logistic regression model to test the risk factors of blood cell line reduction. Our results showed that lower CD4 cell count $<200$ cells $/ \mu \mathrm{L}$ (OR: 3.64, 95\% CI: 2.9-4.58, $p<0.001$ ), femaleness (OR: 2.9, 95\% CI: $2-4.3, p<0.001$ ), WHO stage IV (OR: 2.11, 95\% CI: 1.6-2.79, $p<0.001$ ), coinfection with hepatitis B virus (HBV) (OR: 1.8, 95\% CI: $1.18-2.71, p=0.01)$, BMI $<18.5 \mathrm{~kg} / \mathrm{m}^{2}$ (OR 1.4, 95\% CI: $1.1-1.82, p=0.048$ ), a viral load $>100,000$ (OR: $1.6,95 \%$ CI: $1.28-2, p<0.001$ ), and age $\geq 40$ years (OR: $1.55,95 \% \mathrm{CI}$ : $1.25-1.93, p<0.001)$ were all risk factors of cytopenias (Figure 3(b); Table 3).

3.4. Effect of HAART on Cytopenia. Obvious resolution of cytopenia was observed after 24 months of HAART. The percentage of cytopenia recovery is shown in Table 4 . We found that the proportions of neutropenia, anemia, thrombocytopenia, bicytopenia, and pancytopenia were all decreased after 6,12 , and 24 months of HAART, as shown in 
TABLE 2: The risk factors of cytopenia in HAART-naïve patients.

\begin{tabular}{|c|c|c|c|c|c|}
\hline & $\mathrm{df}$ & Univariate analysis OR ( $95 \% \mathrm{CI})$ & $p$ value & Multivariate analysis AOR (95\% CI) & $p$ value \\
\hline Age (years) & 1 & & & & \\
\hline$<40$ & & Ref & - & Ref & - \\
\hline$\geq 40$ & & $1.5(1.21,1.9)$ & $<0.01$ & $1.51(1.21,1.9)$ & $<0.01$ \\
\hline Sex & 1 & & & & \\
\hline Male & & Ref & - & Ref & - \\
\hline Female & & $2.9(2,4.3)$ & $<0.001$ & $2.92(2,4.28)$ & $<0.001$ \\
\hline WHO stage & 3 & & $<0.001$ & & $<0.001$ \\
\hline I & & Ref & - & Ref & - \\
\hline II & & $0.73(0.44,1.22)$ & 0.064 & $0.73(0.44,1.22)$ & 0.23 \\
\hline III & & $1.03(0.67,1.59)$ & 0.65 & $1.03(0.67,1.59)$ & 0.9 \\
\hline IV & & $1.94(1.45,2.58)$ & $<0.001$ & $1.94(1.45,2.57)$ & $<0.001$ \\
\hline $\mathrm{HCV}$-coinfection & 1 & & & & \\
\hline No & & Ref & - & Ref & - \\
\hline Yes & & $1.8(1.18,2.76)$ & 0.015 & $1.8(1.12,2.87)$ & 0.007 \\
\hline CD4 (cells/ $\mu \mathrm{l})$ & 1 & & & & \\
\hline$\geq 200$ & & Ref & - & Ref & - \\
\hline$<200$ & & $3.57(2.8,4.5)$ & $<0.001$ & $3.57(2.83,4.5)$ & $<0.001$ \\
\hline HIV RNA & 1 & & & & \\
\hline$<100000$ & & Ref & - & Ref & - \\
\hline$\geq 100000$ & & $1.55(1.24,2.58)$ & $<0.001$ & $1.55(1.24,1.92)$ & $<0.001$ \\
\hline BMI & 2 & & 0.034 & & 0.034 \\
\hline $18.5-24$ & & Ref & - & Ref & - \\
\hline$<18.5$ & & $1.6(1.12,2.31)$ & 0.01 & $1.61(1.1,2.32)$ & 0.01 \\
\hline$>24$ & & $1.2(0.9,1.54)$ & 0.23 & $1.18(0.9,1.54)$ & 0.23 \\
\hline Infection routes & 1 & & & & \\
\hline Others & & Ref & - & & \\
\hline Sexual & & $1.27(0.6,2.65)$ & 0.53 & & \\
\hline $\mathrm{HCV}$-coinfection & 1 & & & & \\
\hline No & & Ref & - & & \\
\hline Yes & & $1.94(0.98,3.82)$ & 0.056 & & \\
\hline
\end{tabular}

Note: df, degree of freedom; WHO, World Health Organization; BMI, body mass index; Ref, reference.

Figure 4(a). After antiviral treatment, with the increase in the $\mathrm{CD} 4{ }^{+} \mathrm{T}$-cell count, the absolute count of neutrophils, the absolute platelet counts, and the hemoglobin concentration in cytopenia patients increased sharply up to 6 months of HAART and then slowly after 6 months of therapy (Figures 4(b)-4(d)).

3.5. The Risk Factors for Persistent Cytopenia after 24 Months $H A A R T$. To investigate the risk factors for these patients without persistent cytopenia, a logistic regression analysis was performed. We found that a CD4 cell count of $<200$ cells $/ \mu \mathrm{L}$ at baseline (OR: 2.42, 95\% CI: 1.2-4.86, $p=0.013$ ), femaleness (OR: 5.54, 95\% CI: 2.47-12.42, $p<0.001$ ), coinfection with HBV (OR: 4.84, 95\% CI: 1.47-15.91, $p=0.01$ ), and treatment with AZT (OR: 3.71, 95\% CI: $1.16-11.9, p=0.009)$ were all risk factors for unrecoverable hematological parameters after 24 months of antiviral therapy (Table 5).

\section{Discussion}

In the present study, we found that HAART was an effective treatment for cytopenia patients before the initiation of HAART. Along with the recovery of the CD $4^{+}$ T-cell count, blood cells (neutrophils, platelets, and hemoglobin) were also increased. Femaleness, the lower $\mathrm{CD} 4{ }^{+} \mathrm{T}$-cell count at baseline, an advance stage at baseline, and coinfection with $\mathrm{HBV}$ were risk factors for persistent cytopenia after HAART, which suggested the importance of starting HAART early in cytopenia patients with HIV infection.

There have been a large number of studies about the prevalence of anemia, thrombocytopenia, leucopenia, and neutropenia [26-30], and HIV-1-infected patients often show a reduction in two or three blood cell lines. Furthermore, pancytopenia was linked with higher mortality than nonpancytopenia [31]; however, there have been few studies to investigate this fully. In this study, we found that the most common type of cytopenia was unicytopenia, followed by bicytopenia and pancytopenia. Among unicytopenia, the neutropenia was the most common cytopenia and neutropenia and anemia was the most common bicytopenia.

In this study, CD4 $<200$ cells/ $\mu$, advanced WHO clinical stage, higher HIV viral load, age $\geq 40$ years, and coinfection with $\mathrm{HBV}$ at baseline was identified as the risk factors for cytopenia in the multivariate analysis, a finding consistent with that of the previous studies [32]. The association of low CD4 cell count with cytopenia may be due to the effect of HIV on the function of early hematopoietic progenitor cells [33]. 
TABLE 3: The ordinal logistic regression model of cytopenia in HAART-naïve patients.

\begin{tabular}{|c|c|c|c|}
\hline & $\mathrm{B}$ & AOR $(95 \% \mathrm{CI})$ & $p$ value \\
\hline \multicolumn{4}{|l|}{ Age (years) } \\
\hline$<40$ & Ref & - & - \\
\hline$\geq 40$ & 0.44 & $1.55(1.25,1.93)$ & $<0.001$ \\
\hline \multicolumn{4}{|l|}{ Sex } \\
\hline Male & Ref & - & - \\
\hline Female & 1.064 & $2.9(2,4.3)$ & $<0.001$ \\
\hline \multicolumn{4}{|l|}{ WHO stage } \\
\hline I & Ref & - & - \\
\hline II & -0.3 & $0.74(0.45,1.23)$ & 0.249 \\
\hline III & 0.071 & $1.07(0.7,1.65)$ & 0.74 \\
\hline IV & 0.748 & $2.11(1.6,2.79)$ & $<0.001$ \\
\hline \multicolumn{4}{|c|}{ HBV-coinfection } \\
\hline No & Ref & - & - \\
\hline Yes & 0.58 & $1.8(1.18,2.71)$ & 0.01 \\
\hline \multicolumn{4}{|c|}{ CD4 (cells/ $\mu \mathrm{l})$} \\
\hline$\geq 200$ & Ref & - & - \\
\hline$<200$ & 1.29 & $3.64(2.9,4.58)$ & $<0.001$ \\
\hline \multicolumn{4}{|l|}{ HIV RNA } \\
\hline$<100000$ & Ref & - & - \\
\hline$\geq 100000$ & 0.47 & $1.6(1.28,2)$ & $<0.001$ \\
\hline \multicolumn{4}{|l|}{ BMI } \\
\hline $18.5-24$ & Ref & - & - \\
\hline$<18.5$ & 0.3 & $1.4(1,1.82)$ & 0.048 \\
\hline$>24$ & -0.145 & $0.9(0.66,1.13)$ & 0.28 \\
\hline \multicolumn{4}{|c|}{ Infection routes } \\
\hline Others & Ref & - & - \\
\hline Sexual & -0.246 & $0.78(0.6,1.11)$ & 0.17 \\
\hline \multicolumn{4}{|c|}{ HCV-coinfection } \\
\hline No & Ref & - & - \\
\hline Yes & 0.51 & $1.66(0.85,3.22)$ & 0.14 \\
\hline
\end{tabular}

Note: WHO, World Health Organization; BMI, body mass index; Ref, reference.

TABLE 4: The proportion of cytopenias at baseline and 6, 12, and 24 months after HAART.

\begin{tabular}{lcccc}
\hline Cytopenia & Baseline & At 6 months of HAART & At 12 months of HAART & At 24 months of HAART \\
\hline Neutropenia & $285(46.6 \%)$ & $97(18 \%)$ & $92(15.1 \%)$ & $69(11.3 \%)$ \\
Anemia & $349(57.1 \%)$ & $91(14.9 \%)$ & $56(9.2 \%)$ & $48(7.9 . \%)$ \\
Thrombocytopenia & $118(19.3 \%)$ & $27(4.4 \%)$ & $26(4.3 \%)$ & $15(2.5 \%)$ \\
Unicytopenia & $483(79.1 \%)$ & $155(25.4 \%)$ & $133(21.8 \%)$ & $108(17.7 \%)$ \\
Bicytopenia & $111(18.2 \%)$ & $21(3.4 \%)$ & $16(2.6 \%)$ & $12(2 \%)$ \\
Pancytopenia & $16(2.6 \%)$ & $6(1 \%)$ & $3(0.5 \%)$ & $1(0.2 \%)$ \\
\hline
\end{tabular}

Previous studies have reported that HAART is an effective treatment for anemia, thrombocytopenia, and neutropenia $[16,28,34]$ in HIV-1-infected patients, and the results of our study were consistent with this. We found that the neutrophil count, the platelet count, and the hemoglobin concentration were increased and the proportions of neutropenia, anemia, and thrombocytopenia were decreased after 6 months of HAART. The resolution of cytopenia was associated with the improvement in the $\mathrm{CD}^{+}{ }^{+} \mathrm{T}$-cell count, which indicated that HIV-related cytopenia was caused by HIV-1 and immunosuppression and that virus suppression and immunological reconstitution could prompt the normalization of blood cells.

In accordance with a previous study, we also found that a low $\mathrm{CD}^{+}$T-cell count and advanced staging before the initiation of HAART were predictors of patients with persistent cytopenia after 24 months of HAART. Levine et al. found that HAART use and higher $\mathrm{CD} 4^{+} \mathrm{T}$-cell counts were associated with the resolution of neutropenia [34]. Berhane et al. reported that a CD 4 cell count $<200$ cells/ $\mu \mathrm{L}, \mathrm{HIV}$ RNA $>5000$ copies $/ \mathrm{mL}$, and erythrocyte mean corpuscular volume $<80 \mathrm{fl}$ were independent predictors of anemia after 12 months of HAART [14]. O'Bryan et al. demonstrated that patients with a higher HIV load were at risk of persistent thrombocytopenia after HAART [15]. In the present study, we also found that a low $\mathrm{CD} 4^{+} \mathrm{T}$-cell count was associated with HAART-naive patients with cytopenias, which suggested the advanced stage before initiation of HAART was associated with the risk of cytopenia and the recovery ratio of cytopenia after treatment. More importantly, early detection of HIV could decrease the prevalence of cytopenias, while early initiation of HAART was very important for HIV-1 infected patients with cytopenia. 


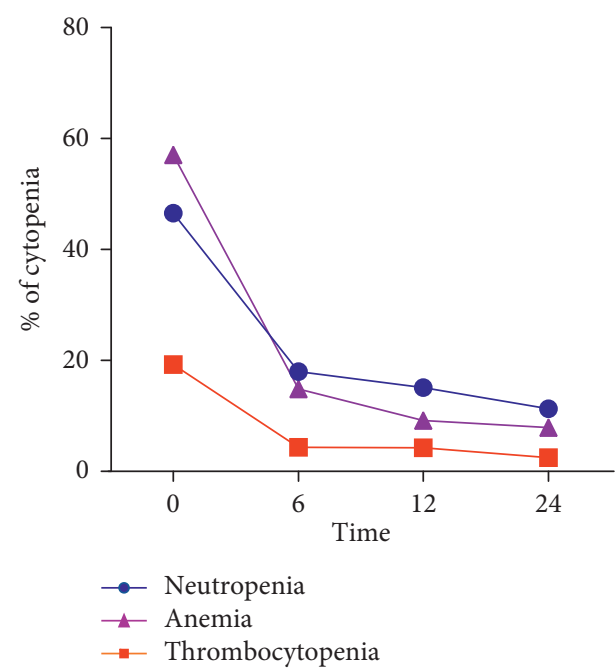

(a)

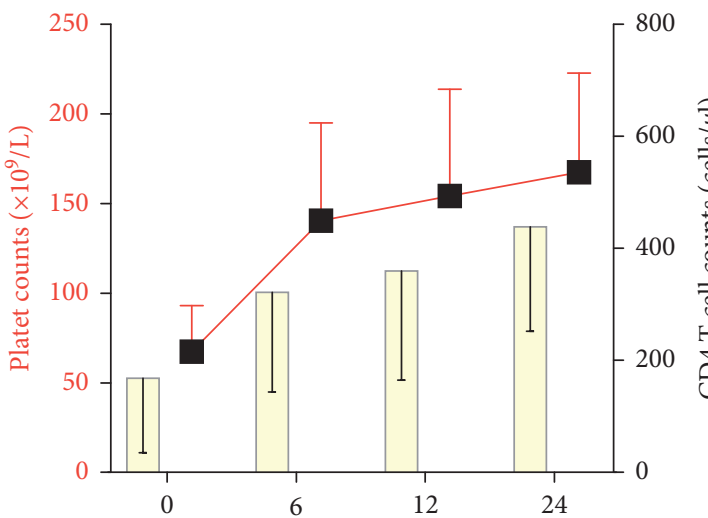

(c)

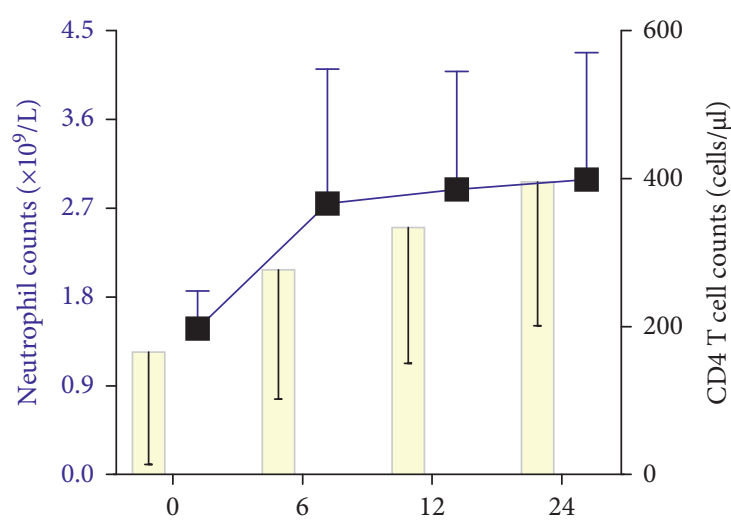

(b)

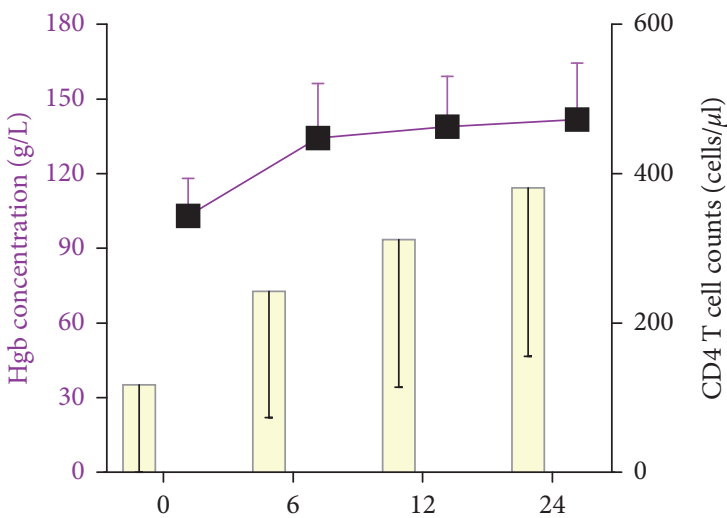

(d)

FIGURE 4: Recovery from cytopenia in patients before the initiation of HAART and after 6, 12, and 24 months of HAART. (a) Recovery from neutropenia, thrombocytopenia, and anemia in patients. (b) Absolute neutrophil count and absolute CD4 $4^{+} \mathrm{T}$-cell count in patients with neutropenia. (c) Absolute platelet counts and absolute $\mathrm{CD}^{+}{ }^{+} \mathrm{T}$-cell count in patients with thrombocytopenia. (d) Hemoglobin concentration and the absolute count of $\mathrm{CD}^{+} \mathrm{T}$ cells in patients with anemia.

TABLE 5: The risk factors of cytopenia with persistent cytopenia after 24 months HAART.

\begin{tabular}{|c|c|c|c|c|c|}
\hline & $\mathrm{df}$ & Univariate analysis, OR (95\% CI) & $p$ value & Multivariate analysis, OR (95\% CI) & $p$ value \\
\hline AZT & 1 & & & & \\
\hline No & & Ref & - & Ref & - \\
\hline Yes & & $4.89(1.49,16.07)$ & 0.009 & $3.71(1.16,11.9)$ & 0.009 \\
\hline Sex & 1 & & & & \\
\hline Male & & Ref & - & Ref & - \\
\hline Female & & $5.42(2.35,12.5)$ & $<0.001$ & $5.54(2.47,12.42)$ & $<0.001$ \\
\hline HBV-coinfection & 1 & & & & \\
\hline No & & Ref & - & Ref & - \\
\hline Yes & & $3.8(1.05,13.95)$ & 0.042 & $4.84(1.47,15.91)$ & 0.01 \\
\hline $\mathrm{CD} 4^{+} \mathrm{T}$-cell counts at baseline & 1 & & & & \\
\hline$\geq 200$ & & Ref & - & Ref & - \\
\hline$<200$ & & $2.47(1.04,5.85)$ & 0.04 & $2.42(1.2,4.86)$ & 0.013 \\
\hline $\mathrm{CD} 4^{+} \mathrm{T}$-cell counts at 24 montl & 1 & & & & \\
\hline$\geq 200$ & & Ref & - & & \\
\hline$<200$ & & $0.58(0.23,1.48)$ & 0.257 & & \\
\hline WHO stage at baseline & 3 & & 0.4 & & \\
\hline I & & Ref & - & & \\
\hline II & & $1.13(0.51,2.5)$ & 0.77 & & \\
\hline
\end{tabular}


TABLE 5: Continued.

\begin{tabular}{|c|c|c|c|c|}
\hline & $\mathrm{df}$ & Univariate analysis, OR (95\% CI) & $p$ value Multivariate analysis, OR $(95 \% \mathrm{CI})$ & $p$ value \\
\hline III & & $4.37(0.93,20.54)$ & 0.124 & \\
\hline IV & & $0.72(0.12,4.21)$ & 0.72 & \\
\hline Age & 1 & & & \\
\hline$<40$ & & Ref & - & \\
\hline$\geq 40$ & & $0.97(0.44,2.15)$ & 0.93 & \\
\hline $\mathrm{D} 4 \mathrm{~T}$ & 1 & & & \\
\hline No & & Ref & - & \\
\hline Yes & & $1.4(0.72,2.73)$ & 0.32 & \\
\hline HCV-coinfection & 1 & & & \\
\hline No & & Ref & - & \\
\hline Yes & & $1.01(0.1,9.96)$ & 0.993 & \\
\hline
\end{tabular}

Note: df, degree of freedom; WHO, World Health Organization; BMI, body mass index; Ref, reference; D4T, stavudine; AZT, zidovudine.

A previous study found that the incidence of cytopenia was $63.2 \%$ in HIV-infected patients in South Africa [35]. Kyeyune et al. reported that the prevalence of cytopenia was $65 \%$, of which $21.9 \%$ of patients had bicytopenia and only $2 /$ 400 patients had pancytopenia [5]. In the present study, we found that the prevalence of cytopenia was $19.1 \%$, and the difference between this result and that of the former study might be due to differences in the population and the geographical location.

The present study found that the ratio of recovery was $68.2 \%$ in patients with cytopenia after 6 months HAART, and $76.4 \%$ of patients with cytopenia returned to normal blood cell levels after 24 months HAART. After 6 months of antiviral therapy, the increase in blood cells obviously slowed down. The main reasons for this were that viral replication was suppressed and immunity was improved by 6 months of HAART, and HIV-1 related cytopenia caused by myelosuppression was relieved. Other factors such as malnutrition and a patient's economic situation may play a role in persistent cytopenia after 6 months of HAART.

It is not only HIV-1, but also HAART such as AZT, that can lead to persistent hematopoietic suppression and resulting cytopenia [3, 17]. In our study, among cytopenia patients with persistent cytopenia after 24 months of HAART, AZT was used in 28 patients. We also found that persistent cytopenia was associated with the effects of AZT.

There are some limitations to our study. First, there was potential inherent bias in a retrospective observational study. Second, most of the participants in the present study were urban residents of Beijing, who are not necessarily representative of all HIV-infected patients in China.

\section{Conclusion}

The prevalence of cytopenia in patients before the initiation of HAART was $19.1 \%$, of which the prevalence of unicytopenia, bicytopenia, and pancytopenia was $15.3 \%$, $3.3 \%$, and $0.4 \%$, respectively. Cytopenia was associated with femaleness, a lower BMI, a lower $\mathrm{CD} 4^{+} \mathrm{T}$-cell count, a higher viral load, WHO stage IV, and coinfection with
HBV. HAART was an effective treatment for cytopenia, and along with the $\mathrm{CD} 4^{+} \mathrm{T}$-cell count, the blood cell count was also increased. Persistent cytopenia after 24 months of HAART was associated with femaleness, coinfection with $\mathrm{HBV}$, a $\mathrm{CD} 4^{+} \mathrm{T}$-cell count at baseline, and WHO stage IV at baseline. Early initiation of HAART and combination antiretroviral therapy without AZT seems to promote the recovery of HIV-infected patients with cytopenia.

\section{Data Availability}

The clinical data used to support the findings of this study have not been made available because of patient privacy.

\section{Disclosure}

The funders played no role in study design, data collection, analysis, the decision to publish, or preparation of the manuscript.

\section{Conflicts of Interest}

The authors declare no conflicts of interest regarding the publication of this article.

\section{Authors' Contributions}

Hongxin Zhao conceived and designed the experiments; Lina Fan and Cuilin Li were involved in the acquisition of data and analyzed the data. Lina Fan wrote the manuscript.

\section{Acknowledgments}

We acknowledge the work of HIV health care providers for their diagnosis, nursing, and treatment of HIV/AIDS patients in Ditan Hospital. We also thank International Science Editing (http://www.internationalscienceediting.com) for editing this manuscript. This work was supported by the grants from the National Natural Science Foundation of China (No. 81672000) and the Thirteen-fifth Key Project (No. 2018ZX10715-005). 


\section{References}

[1] P. S. Belperio and D. C. Rhew, "Prevalence and outcomes of anemia in individuals with human immunodeficiency virus: a systematic review of the literature," The American Journal of Medicine, vol. 116, no. 7, pp. 27-43, 2004.

[2] N. Mir, C. Costello, J. Luckit, and R. Lindley, "HIV-disease and bone marrow changes: a study of 60 cases," European Journal of Haematology, vol. 42, no. 4, pp. 339-343, 1989.

[3] X. Shi, M. D. Sims, M. M. Hanna et al., "Neutropenia during HIV infection: adverse consequences and remedies," International Reviews of Immunology, vol. 33, no. 6, pp. 511-536, 2014.

[4] B. Dikshit, A. Wanchu, R. K. Sachdeva, A. Sharma, and R. Das, "Profile of hematological abnormalities of Indian HIV infected individuals," BMC Hematology, vol. 9, no. 1, p. 5, 2009.

[5] R. Kyeyune, E. Saathoff, A. E. Ezeamama, T. Löscher, W. Fawzi, and D. Guwatudde, "Prevalence and correlates of cytopenias in HIV-infected adults initiating highly active antiretroviral therapy in Uganda," BMC Infectious Diseases, vol. 14, no. 1, p. 496, 2014.

[6] G. Dai, J. Xiao, G. Gao et al., "Anemia in combined antiretroviral treatment-naive HIV-infected patients in China: a retrospective study of prevalence, risk factors, and mortality," BioScience Trends, vol. 10, no. 6, pp. 445-453, 2016.

[7] D. R. Kuritzkes, "Neutropenia, neutrophil dysfunction, and bacterial infection in patients with human immunodeficiency virus disease: the role of granulocyte colony-stimulating factor," Clinical Infectious Diseases, vol. 30, no. 2, pp. 256-270, 2000.

[8] E. J. Santiago-Rodríguez, A. M. Mayor, D. M. FernándezSantos, Y. Ruiz-Candelaria, and R. F. Hunter-Mellado, "Anemia in a cohort of HIV-infected Hispanics: prevalence, associated factors and impact on one-year mortality," $B M C$ Research Notes, vol. 7, no. 1, p. 439, 2014.

[9] Z. Tamir, J. Alemu, and A. Tsegaye, "Anemia among HIV infected individuals taking art with and without zidovudine at Addis Ababa, Ethiopia," Ethiopian Journal of Health Sciences, vol. 28, no. 1, pp. 73-82, 2018.

[10] L. Gedefaw, T. Yemane, Z. Sahlemariam, and D. Yilma, "Anemia and risk factors in HAART naive and HAART experienced HIV positive persons in south west Ethiopia: a comparative study," PLoS One, vol. 8, no. 8, Article ID e72202, 2013.

[11] M. A. Jacobson, R. C. Liu, D. Davies, and P. T. Cohen, "Human immunodeficiency virus disease-related neutropenia and the risk of hospitalization for bacterial infection," Archives of Internal Medicine, vol. 157, no. 16, pp. 1825-1831, 1997.

[12] A. Johannessen, E. Naman, S. G. Gundersen, and J. N. Bruun, "Antiretroviral treatment reverses HIV-associated anemia in rural Tanzania," BMC Infectious Diseases, vol. 11, no. 1, p. 190, 2011.

[13] R. D. Moore and D. Forney, "Anemia in HIV-infected patients receiving highly active antiretroviral therapy," JAIDS Journal of Acquired Immune Deficiency Syndromes, vol. 29, no. 1, pp. 54-57, 2002.

[14] K. Berhane, R. Karim, M. H. Cohen et al., "Impact of highly active antiretroviral therapy on anemia and relationship between anemia and survival in a large cohort of HIV-infected women: women's interagency HIV Study," JAIDS Journal of Acquired Immune Deficiency Syndromes, vol. 37, no. 2, pp. 1245-1252, 2004.
[15] T. A. O’Bryan, J. F. Okulicz, W. P. Bradley, A. Ganesan, X. Wang, and B. K. Agan, "Impact of the highly active antiretroviral therapy era on the epidemiology of primary HIV-associated thrombocytopenia," BMC Research Notes, vol. 8, no. 1, p. 595, 2015.

[16] G. G. Woldeamanuel and D. H. Wondimu, "Prevalence of thrombocytopenia before and after initiation of HAART among HIV infected patients at black lion specialized hospital, Addis Ababa, Ethiopia: a cross sectional study," BMC $\mathrm{He}$ matology, vol. 18, no. 1, p. 9, 2018.

[17] P. Koka and S. Reddy, "Cytopenias in HIV infection: mechanisms and alleviation of hematopoietic inhibition," Current HIV Research, vol. 2, no. 3, pp. 275-282, 2004.

[18] H.-W. Fan, F.-P. Guo, Y.-J. Li, N. Li, and T.-S. Li, "Prevalence of thrombocytopenia among Chinese adult antiretroviralnaïve HIV-positive patients," Chinese Medical Journal, vol. 128, no. 4, pp. 459-464, 2015.

[19] X. Shi, P. Zhang, G. D. Sempowski, and J. E. Shellito, "Thymopoietic and bone marrow response to murine Pneumocystis pneumonia," Infection and Immunity, vol. 79, no. 5, pp. 2031-2042, 2011.

[20] Z. D. Zhang, Blood Disease Diagnosis and Efficacy Criteria, Science Press, Beijing, China, 2007.

[21] AIDS, Heptitis C Professional Group SoID, Chinese Medical Association, and Chinese Center for Disease Control and Prevention, "Chinese guidelines for diagnosis and treatment of HIV/AIDS (2018)," Chinese Jouranl of International Medicine, vol. 57, pp. 1-18, 2008.

[22] World Health Organization, WHO Case Definitions of HIV for Surveillance and Revised Clinical Staging and Immunological Classification of HIV-Related Disease in Adults and Children, World Health Organization, Geneva, Switzerland, 2007.

[23] C. M. Chen, "Overview of obesity in mainland China," Obesity Reviews, vol. 9, no. s1, pp. 14-21, 2008.

[24] M. J. Jin, B. B. Chen, Y. Y. Mao et al., "Prevalence of overweight and obesity and their associations with socioeconomic status in a rural Han Chinese adult population," PLoS One, vol. 8, no. 11, Article ID e79946, 2013.

[25] C. L. Smith and G. E. Stein, "Viral load as a surrogate end point in HIV disease," The Annals of Pharmacotherapy, vol. 36, pp. 280-287, 2002.

[26] A. Moses, J. Nelson, and G. C. Bagby Jr., "The influence of human immunodeficiency virus-1 on hematopoiesis," Blood, vol. 91, pp. 1479-1495, 1998.

[27] D. W. Gunda, K. G. Godfrey, S. B. Kilonzo, and B. C. Mpondo, "Cytopenias among ART-naive patients with advanced HIV disease on enrolment to care and treatment services at a tertiary hospital in Tanzania: a crosssectional study," Malawi Medical Journal, vol. 29, no. 1, pp. 43-52, 2017.

[28] T. Deressa, D. Damtie, M. Workineh, M. Genetu, and M. Melku, "Anemia and thrombocytopenia in the cohort of HIV-infected adults in northwest Ethiopia: a facility-based cross-sectional study," Electronic journal of the International Federation of Clinical Chemistry and Laboratory Medicine, vol. 29, pp. 36-47, 2018.

[29] C. Firnhaber, L. Smeaton, N. Saukila et al., "Comparisons of anemia, thrombocytopenia, and neutropenia at initiation of HIV antiretroviral therapy in Africa, Asia, and the Americas," International Journal of Infectious Diseases, vol. 14, no. 12, pp. e1088-e1092, 2010.

[30] P. Hermans, B. Sommereijns, N. Van Cutsem, and N. Clumeck, "Neutropenia in patients with HIV infection: a case control study in a cohort of 1403 patients between 1982 
and 1993," Journal of Hematotherapy \& Stem Cell Research, vol. 8, no. 1, pp. S23-S32, 1999.

[31] E. Santiago-Rodriguez, A. Mayor, D. Fernandez-Santos, and R. Hunter-Mellado, "Profile of HIV-infected hispanics with pancytopenia," International Journal of Environmental Research and Public Health, vol. 13, no. 1, 2015.

[32] S. Y. Choi, I. Kim, N. J. Kim et al., "Hematological manifestations of human immunodeficiency virus infection and the effect of highly active anti-retroviral therapy on cytopenia," The Korean Journal of Hematology, vol. 46, no. 4, pp. 253-257, 2011.

[33] F. Kirchhoff and G. Silvestri, "Is Nef the elusive cause of HIVassociated hematopoietic dysfunction?," Journal of Clinical Investigation, vol. 118, pp. 1622-1625, 2008.

[34] A. M. Levine, R. Karim, W. Mack et al., "Neutropenia in human immunodeficiency virus infection: data from the women's interagency HIV study," Archives of Internal Medicine, vol. 166, no. 4, pp. 405-410, 2006.

[35] J. L. Vaughan, T. M. Wiggill, N. Alli, and K. Hodkinson, "The prevalence of HIV seropositivity and associated cytopenias in full blood counts processed at an academic laboratory in Soweto, South Africa," South African Medical Journal, vol. 107, no. 3, pp. 264-269, 2017. 